\title{
Dukungan Keluarga dengan Prestasi Belajar Siswa Kelas IV Sekolah Dasar
}

\section{Putri Viola Melisa ${ }^{1 *}$, ED Putra ${ }^{2}$}

\author{
1,2 Program Studi Pendidikan Guru Sekolah Dasar, Universitas Islam Riau, Pekanbaru, Indonesia
}

\section{ART ICLE IN F O}

Article history:

Received June 08, 2021

Revised June 10, 2021

Accepted July 30, 2021

Available online August 25, 2021

Kata Kunci:

Dukungan Keluarga, Prestasi

Belajar Siswa

\section{Keywords:}

Family Support, Student

Achievement

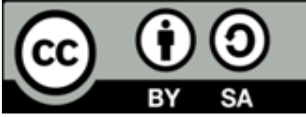

This is an open access article under the CC BY-SA license.

Copyright $(2021$ by Author. Published by Universitas Pendidikan Ganesha.

\begin{abstract}
A B S T R A K
Permasalahan saat ini masih banyak siswa yang memiliki prestasi belajar yang rendah. Salah satu dampak penurunan dari prestasi belajar adalah mendapatkan nilai yang kurang dari KKM (Kriteria Ketuntasan Minimal) yang telah ditetapkan di sekolah sehingga anak harus melakukan remedial untuk memperbaiki nilai sesuai dengan batas yang telah ditetapkan atau tidak lulus Ujian Nasional (UN). Tujuan penelitian ini untuk menganalisis hubungan dukungan keluarga dengan prestasi belajar siswa kelas IV Sekolah Dasar. Jenis penelitian ini merupakan penelitian kuantitatif yang bersifat deskriptif korelatif dengan desain cross sectional. Populasi dalam penelitian ini adalah seluruh wali murid kelas IV Sekolah Dasar sebanyak 56 orang. Teknik pengambilan sempel menggunakan probability sampling dengan simple random samplin, jadi total sampel yang diambil dalam penelitian sebanyak 49 orang.metode pengumpulan data menggunakan kuesioner. Teknik pengolahan data yaitu editing, coding, tabulasi dan entry. Hasil penelitian menunjukkan dukungan keluarga kategori yang baik sebanyak 23 orang (46,9\%) dengan prestasi belajar kategori yang tinggi (memenuhi $\mathrm{KKM} \geq 77$ ) sebanyak 28 orang $(57,1 \%)$ dari 49 responden dengan tingkat kepercayaan 95\%. Maka, terdapat hubungan dukungan keluarga dengan prestasi belajar siswa kelas IV sekolah dasar. Implikasi penelitian ini diharapkan dapat memberikan dampak terhadap prestasi belajar siswa, sehingga tujuan pembelajaran dapat tercapai.
\end{abstract}

\section{A B S TRACT}

The problem today is that there are still many students who have low learning achievement. One of the impacts of the decline in learning achievement is getting a score that is less than the KKM (Minimum Completeness Criteria) that has been set at school, so that children must take remedial measures to improve their scores according to the limits that have been set or not pass the National Examination (UN). This study aimed to analyze the relationship between family support and learning achievement of fourth-grade elementary school students. This type of research is a quantitative descriptive correlative research with a cross-sectional design. The population in this study were all guardians of the fourth-grade elementary school students, as many as 56 people. The sampling technique used probability sampling with simple random sampling, so the total sample taken in the study was 49 people. The data collection method used a questionnaire. Data processing techniques are editing, coding, tabulation, and entry. The results showed that there were 23 good category family support (46.9\%) with a high learning achievement category (meets $K K M \geq 77$ ) as many as 28 people $(57.1 \%)$ of 49 respondents with a 95\% confidence level. So, there is a relationship between family support and the learning achievement of fourth-grade elementary school students. The implications of this research are expected to impact student achievement so that learning objectives can be achieved.

\section{PENDAHULUAN}

Pada dasarnya pendidikan merupakan upaya mengoptimalkan dari kemampuan anak memperoleh keunggulan dalam bidang intelektual dan sikap moral. Upaya mengoptimalkan kemampuan anak dapat dilihat dari prestasi belajarnya (Mariyana, 2020; Rizki et al., 2017). Prestasi belajar merupakan tingkat kemanusiaan yang dimiliki siswa dalam menerima, menolak, dan menilai informasi-informasi yang diperoleh dalam proses belajar mengajar (Sari et al., 2021; Saripudin et al., 2018). Prestasi siswa 
dipengaruhi oleh faktor dalam serta faktor luar diri sisiwa. Salah satu faktor yang mempengaruhi adalah faktor dukungan orang tua dalam proses pembelajaran. Salah satu dukungan yang bisa dilakukan oleh orang tua adalah memberikan dorongan atau motivasi kepada siswa untuk belajar lebih baik untuk tercapainya prestasi yang diinginkan (Kuswariningsih, 2016; Nur, 2016). Dukungan keluarga menjadi bentuk sikap tindakan dan penerimaan keluarga terhadap anggota keluarga berupa dukungan informasional, dukungan penilaian, dukungan instrumental dan dukungan emosional (Perceka, 2020; Safitri \& Yuniwati, 2019). Memberikan bantuan dan pertolongan apabila diperlukan yang bersifat mendukung kepada anggota keluarga (Garbe et al., 2020; Inten, 2017). Penerimaan keluarga terhadap anggotanya dalam bentik sikap dan tindakan. Anggota keluarga memandang bahwa anggota keluarga yang bersifat mendukung akan selalu siap memberikan bantuan dan pertolongan jika dibutuhkan. Dukungan keluarga adalah suatu bentuk hubungan interpersonal yang melindungi seseorang dari efek stres yang buruk (Lestari et al., 2020; Safitri \& Yuniwati, 2019)). Lingkungan keluarga setiap individu atau siswa memerlukan dukungan orang tua dalam mencapai prestasi belajar, karena dukungan dan perhatian keluarga ini akan menentukan seseorang siswa dapat mencapai prestasi belajar yang tinggi (Choe, 2020; Curtis et al., 2021). Dukungan keluarga diwujudkan dalam hal kasih sayang , memberi nasehat-nasehat dan sebagainya. Selain itu perasaan empati dan penerimaan merupakan bentuk perilaku yang diberikan oleh keluarga akan semakin membantu untuk mewujudkan semangat siswa dalam proses belajar (G. J Hwang et al., 2020; Yulianti et al., 2016). Jadi dengan adanya dukungan kelauaraga akan memberikan ampak yang Positif terhadap prestasi be;ajar siswa.

Namun permasalahan yang terjadi, masih banyak siswa yang memiliki prestasi belajar yang rendah. Usia anak sekolah dasar mulai 6-12 tahun merupakan usia yang rentan mengalami penurunan prestasi belajar di sekolah (Hamdu, 2011; Sunarti et al., 2016). Salah satu dampak penurunan dari prestasi belajar adalah mendapatkan nilai yang kurang dari KKM (Kriteria Ketuntasan Minimal) yang telah ditetapkan di sekolah sehingga anak harus melakukan remedial untuk memperbaiki nilai sesuai dengan batas yang telah ditetapkan atau tidak lulus Ujian Nasional (UN) (Astika et al., 2018). Berdasarkan hasil wawancara penulis di SDN 134 Pekanbaru pada tanggal 18 Februari 2021 dengan wali kelas 4 (A dan B) dan 7 orang tua wali murid kelas 4A dan 4B. Adapun dari Hasil wawancara saya dengan wali kelas 4A dan 4B sebagai berikut batas KKM seluruh mata pelajaran adalah nilai : 77), tidak semua nilai siswa kelas 4A dan 4B memenuhi batas standar nilai KKM maka dilakukan remedial dengan memberikan tugas untuk bisa mencapai KKM (26 orang (kelas 4 A) nilai yang mencapai KKM setelah dilakukan remedial sebelumnya sebanyak 15 orang), sedangkan di kelas 4B 24 orang yang mencapai nilai KKM setelah dilakukan remedial sebelumnya sebanyak 17 orang. Kendala atau hambatan dalam proses pembelajaran pada siswa pada saat ini yaitu pada kondisi pandemi covid saat ini ada beberapa orang siswa yang tidak mengikuti proses pembelajaran disebabkan tidak memilki HP, paket data sehingga siswa tersebut tidak dapat informasi ujian dan tugas yang diberikan oleh guru yang bersangkutan. Yang berdampak terhadap penurunan prestasi siswa sekolah dasar karena banyak siswa yang tidak mengerti mengenai materi pelajaran sehingga mengerjakan tugas dari guru. Serta, kendala yang diahadapi orang tua adalah, 4 orang (57\%) diantaranya kurang memperhatikan mengenai prestasi belajar anak dengan alasan sibuk kerja sehingga dia tidak ada waktu untuk menanyakan tugas dari guru di Sekolah, tidak bisa mendampingi belajar anaknya selain sibuk bekerja dan tidak mengerti dan lain-lain yang menyebabkan penurunan prestasi anak dalam belajar. Salah satu orang tua wali murid mengatakan siswa memiliki kemampuan untuk mengerjakan tugas yang diberikan oleh guru di sekolah tetapi anak zaman sekarang mereka sudah sibuk dengan Handphone (HP). Handphone dijadikan alasan mengerjakan tugas tetapi main game online sehingga anak tersebut menjadi malas mengerjakan tugas-tugas yang diberikan oleh guru di sekolah. Akibat anak ketinggalan pelajaran, tugas menjadi menumpuk dan membuat anak sukar untuk mengerjakan tugas mereka kembali bahkan ada yang harus mengulang (remedial) untuk memperbaiki nilai sesuai batas KKM yang sudah ditentukan oleh masing-masing Sekolah. Penyebab penurunan prestasi belajar diantaranya oleh faktor internal (dari dalam diri siswa), keadaan jasmani dan rohani yang ada dalam diri siswa dan faktor ekternal (lingkungan siswa) yaitu kondisi lingkungan siswa atau keluarga siswa. Lingkungan keluarga dalam perspektif ilmu pendidikan merupakan yang pertama dan utama.

Berdasarakan jabaran tersebut dapat diakatakan bahwa dukungan orang tua dalam proses pembelajaran khususnya pembelajaran daring saat ini sangatlah penting. Oleh sebab itu perlu dilakukan sebuah kajian tentang dukungan orang tua terhadap peningkatakan prestasi siswa. Beberapa temuan penelitian sebelumnya menyatakan ada pengaruh dukungan keluarga terhadap prestasi belajar (Safitri \& Yuniwati, 2019). Selain itu, semakin tinggi dukungan keluarga maka semakin tinggi pula motivasi belajar siswa pada masa pandemi Covid-19 (Saragih et al., 2021). Dukungan keluarga juga memberikan kontribusi terhadap motivasi belajar siswa, dengan motivasi yang baik akan meningkatkan prestasi belajar siswa(Fitria \& Barseli, 2021). Keluarga memberikan pengaruh yang besar dalam keberhasilan 
belajar siswa (T. T. Sari, 2020). Penelitian ini bertujuan untuk menganalisis hubungan dukungan keluarga dengan prestasi belajar siswa kelas IV SDN 134 Pekanbaru Tahun 2021".

\section{METODE}

Jenis penelitian ini adalah Kuantitatif yang bersifat deskriptif korelatif dengan desain cross sectional. Desain penelitian cross sectional adalah penelitian yang dilakukan dalam satu waktu tertentu. Penelitian ini hanya digunakan dalam waktu tertentu dan tidak akan dilakukan penelitian lain di waktu yang berbeda untuk di perbandingkan. Penelitian dilakukan di SDN 134 Pekanbaru di Jl. Samanhudi Nomor. 12 Sago, Kecamatan Senapelan, Kota Pekanbaru, Riau. Populasi penelitian adalah keseluruhan subjek atau objek yang akan diteliti (Notoatmodjo, 2010 : 115). Populasi dalam penelitian ini adalah seluruh wali murid kelas IV (A dan B) Sekolah Dasar Negeri 134 Pekanbaru tahun ajaran 2020/2021 sebanyak 56 orang. Sampel penelitian adalah bagian dari subjek atau objek yang akan diteliti atau bagian populasi penelitian yang dianggap mewakili seluruh populasi yang akan diteliti. Sampel dalam penelitian ini adalah bagian dari wali murid kelas IV (A dan B) Sekolah Dasar Negeri 134 Pekanbaru tahun ajaran 2020/2021 dijadikan sampel penelitian yang diambil secara acak sederhana atau dengan undian. Teknik sampel dalam penelitan ini adalah Probability Sampling dengan simple random sampling. Simple Random Sampling atau acak sederhana adalah pengambilan sampel dengan cara acak tanpa memperhatikan strata yang ada dalam anggota populasi. Pengambilan sampel dilakukan dengan undian sebanyak sampel yang telah ditentukan dengan menggunakan rumus besar sampel. Jadi total sampel yang diambil dalam penelitian sebanyak 49 orang. Variabel Penelitian adalah Variabel Dependen dan Independent. Instrumen penelitian adalah alat-alat yang digunakan untuk pengumpulan data. Penelitian ini menggunakan instrumen (alat) penelitian berupa angket atau kuesioner. Angket adalah suatu cara pengumpulan data atau suatu penelitian mengenai masalah yang umumnya banyak menyangkut kepentingan umum (orang banyak). Angket ini dilakukan dengan mengedarkan suatu daftar pertanyaan berupa formulir-formulir yang diajukan secara tertulis kepada sejumah subjek untuk mendapatkan tanggapan, informasi, jawaban dan sebagainya.

Sumber Data yaitu data primer dalam penelitian ini adalah data yang diperoleh langsung dari responden melalui kuesioner. Data primer yaitu data pendidikan, pekerjaan dan dukungan keluarga (dukungan informasional, dukungan emosional, dukungan instrumen dan dukungan penilaian. Data Sekunder yaitu data yang diperoleh dari instansi pemerintahan bersumber dari SDN 134 Pekanbaru. Data yang diperoleh yaitu data jumlah siswa kelas IV dan prestasi siswa (nilai ujian akhir semester yang memenuhi standar KKM). Uji Validitas dan Reabilitas. Uji Validitas yaitu suatu instrumen apabila mampu mengukur apa yang diinginkan dan dapat mengungkapkan data dari variabel penelitian secara tepat. Uji validitas dalam penelitian ini menggunakan Product Moment dari Person. Hasil uji validitas menunjukkan 20 pernyataan dinyatakan valid, karena nilai rhitung (Corrected Item-Total Correlation) $>\mathrm{r}$ tabel sebesar 0,514. Hasil koefisien reliabilitas instrument variabel dukungan keluarga adalah sebesar $r$ alpha $=0,937$, instrument materi pelatihan adalah sebesar $r$ kritis $=0,600$, memiliki nilai "Alpha Cronbach" lebih besar dari 0,600, artinya instrumen (kuesioner) dinyatakan reliable atau memenuhi persyaratan.

Teknik pengolahan data yaitu editing, coding, tabulasi dan entry. Proses editing yaitu memeriksa data yang telah dikumpulkan berupa daftar pertanyaan atau kuesioner dengan cara melakukan penjumlahan dan koreksi. Penjumlahan adalah menghitung banyaknya lembaran dari daftar pertanyaan yang telah diisi untuk mengetahui apakah sesuai dengan jumlah yang telah ditentukan. Coding yaitu pemberian kode yang tujuan untuk mempermudah pengolahan, terutama variabel data klasifikasi. Pemberian kode dilakukan sebelum atau sesudah pengumpulan data dilaksanakan. Pengolahan selanjutnya kode tersebut dikembalikan lagi pada variabel aslinya. Tabulasi adalah penyusunan data merupakan pengorganisasian data sedemikian rupa agar dengan mudah untuk dijumlah, disusun dan ditata untuk disajikan dan dianalisis. Entry adalah Data yang dalam bentuk "kode" (angka atau huruf) dimasukkan ke dalam program u "sofware" computer. Dalam proses ini dituntut ketelitian dari orang yang melakukan " data entry" ini. Apabila tidak maka terjadi bias meskipun hanya memasukkan data.

Metode analisis data yaitu data univariat dilakukan dengan analisis deskriptif untuk melihat karakteristik masing-masing variabel yang diteliti. Data katagorik akan dilihat distribusi frekuensi dengan ukuran presentase atau proporsi, sedangkan data numerik akan dilihat mean dan standar deviasi. Hasil analisis data akan disajikan dalam bentuk tabel, grafik, atau narasi. Analisa univariat atau variabel yang dianalisis dalam penelitian ini adalah Data karakteristik responden dan variabel independen umur responden, pendidikan responden, pekerjaan responden dan data dukungan keluarga (dukungan informasional, dukungan emosional, dukungan instrumen dan dukungan penilaian. Data variabel dependen yaitu data prestasi belajar anak siswa Sekolah Dasar Negeri 134 Pekanbaru. Semua data tersebut berbentuk kategori oleh karena itu dilakukan analisis dan dituangkan dalam bentuk tabel 
distribusi frekuensi. Analisa bivariat dilakukan untuk mengetahui adanya hubungan dukungan keluarga dengan prestasi belajar pada wali murid siswa kelas IV SD. Pengelolaan analisa bivariat ini menggunakan software SPSS 22.0. uji statistic yang digunakan adalah chi-square dengan $\alpha=0,05$. Data atau variabel berisi skala nominal dan nominal. Uji chi-square merupakan salah satu uji statistik non parametrik (distribusi dimana besaran-besaran populasi tidak diketahui) cukup sering digunakan dalam penelitian yang menggunakan dalam 2 variabel, dimana skala 2 variabel adalah nominal atau menguji perbedaan dua atau lebih proporsi sampel. Uji chi-square diterapkan pada kasus dimana akan diuji apakah frekuensi yang diamati (data observasi) untuk membuktikan atau ada perbedaan secara nyata atau tidak dengan frekuensi yang diharapkan.

\section{HASIL DAN PEMBAHASAN}

\section{Hasil}

Berdasarkan hasil perhitungan dari analisis univariat dilakukan pada seluruh variabel secara deskriptif yang bertujuan untuk mengetahui distribusi frekuensi dan persentase dari masing-masing variabel seperti karakteristik responden yaitu pengasuh anak, umur, pendidikan, pekerjaan dan variabel dukungan keluarga (dukungan informasional, dukungan emosional, dukungan instrumen dan penilaian). Mayoritas pengasuh anak (wali siswa) yaitu ibu sebanyak 40 orang $(81,6 \%$ ) dan minoritas kakak dan nenek sebanyak 1 orang (2,0\%). Pada kelompok karakteristik umur responden mayoritas umur 20-49 tahun sebanyak 48 orang (98\%) dan minoritas umur >49 tahun sebanyak 1 orang (1\%), pendidikan responden mayoritas SMA sebanyak 25 orang (51\%) dan minoritas tidak tamat sekolah atau tidak tamat SD sebanyak 3 orang $(6,1 \%)$ dan pekerjaan responden mayoritas IRT sebanyak 24 orang (49\%) dan minoritas Dll (Buruh Harian Lepas) sebanyak 3 orang (6,1\%). Dengan kondisi seperti ini diperoleh mayoritas dukungan keluarga baik sebanyak 23 orang (46,9\%), dukungan keluarga sedang sebanyak 14 orang (28,6\%) dan dukungan keluarga kurang sebanyak 12 oranf (24,5\%) serta prestasi belajar menunjukkan mayoritas prestasi tinggi (memenuhi KKM >=77) sebanyak 28 orang (57,1\%) dan prestasi rendah (tidak memenuhi KKM $<77$ sebanyak 21 orang $(42,9 \%)$. Untuk memperjelas hubungan antara dukungan orang tua dan prestasi belajar data yang diperoleh kemudian dianalisis dan diperoleh hasil mayoritas dukungan keluarga baik dengan prestasi siswa yang tinggi sebanyak 20 orang (40,8\%) dan prestasi siswa yang rendah sebanyak 3 orang $(6,1 \%)$. Dukungan keluarga sedang dengan prestasi siswa tinggi sebanyak 4 orang (8,2\%) dan prestasi siswa rendah sebanyak 10 orang $(20,4 \%)$. Dukungan keluarga kurang dengan prestasi siswa tinggi sebanyak 4 orang $(8,2 \%)$ dan prestasi siswa rendah sebanyak 8 orang $(16,3 \%)$. Hasil dari uji statistik dengan meenggunakan uji chi square diperoleh nilai $\mathrm{p}=0,000$ atau 0,001 maka $<\alpha=0,05$. Hal ini memiliki makna hipotesis H0 ditolak, Ha diterima yaitu ada hubungan dukungan keluarga dengan prestasi siswa kelas IV SD Negeri 134 Pekanbaru. Lebih lengkap hasil analisis di tunjukkan pada tabel 1.

Tabel 1. Tabulasi Silang antara Dukungan Keluarga Pada Siswa Kelas IV SD Negeri 134 Pekanbaru

\begin{tabular}{|c|c|c|c|c|c|c|c|c|}
\hline \multirow{3}{*}{ No } & \multirow{3}{*}{ Dukungan Keluarga } & \multicolumn{4}{|c|}{ Prestasi Siswa } & \multirow{3}{*}{\multicolumn{2}{|c|}{ Total }} & \multirow{3}{*}{$p$} \\
\hline & & \multicolumn{2}{|c|}{ Tinggi } & \multicolumn{2}{|c|}{ Rendah } & & & \\
\hline & & $\mathbf{F}$ & $\%$ & $\mathbf{F}$ & $\%$ & & & \\
\hline 0 & Baik & 20 & 40,8 & 3 & 6,1 & 23 & 46,9 & \\
\hline 1 & Sedang & 4 & 8,2 & 10 & 20,4 & 14 & 28,6 & 0,001 \\
\hline \multirow[t]{2}{*}{2} & Kurang & 4 & 8,2 & 8 & 16,3 & 12 & 24,5 & \\
\hline & Jumlah & 28 & 57,1 & 21 & 42,9 & 49 & 100 & \\
\hline
\end{tabular}

Berdasarkan dari hasil penelitian terhadap 49 responden pada tabel 4 di atas menunjukkan bahwa dukungan keluarga pada siswa SD Negeri 134 Pekanbaru yang mayoritas dengan kategori baik sebanyak 23 orang (46,9\%). Berdasarkan hasil kuesioner dukungan keluarga jawaban tertinggi dari 4 indikator kuesioner tersebut yaitu dukungan informasional sebanyak 21 orang $(42,9 \%)$ dan dukungan instrument sebanyak 22 orang (44,9\%). Prestasi belajar siswa di SD Negeri 134 Pekanbaru yang termasuk dalam kategori prestasi belajar yang tinggi (Memenuhi KKM $\geq 77$ ) yaitu sebanyak 28 orang $(57,1 \%)$ sesuai dengan hasil ujian akhir semester dengan rata rata 77 untuk kelas IV. Hasil dari uji statistik dengan meenggunakan uji chi square diperoleh nilai $\mathrm{p}=0,000$ atau 0,001 maka $<\alpha=0,05$. Hal ini memiliki makna hipotesis H0 ditolak, Ha diterima yaitu ada hubungan dukungan keluarga dengan prestasi siswa kelas IV SD Negeri 134 Pekanbaru. Hal ini sesuai dengan dukungan keluarga kategori yang baik sebanyak 23 orang $(46,9 \%)$ dengan prestasi belajar kategori yang tinggi (memenuhi $\mathrm{KKM} \geq 77$ ) sebanyak 28 orang $(57,1 \%)$ 
dari 49 responden dengan tingkat kepercayaan 95\%. Berdasarakan hasil penelitian ini dapat dikatakan bahwa dukungan oarang tua akan mempengaruhi kerberhasilan siswa dalam melakukan pembelajaran.

Lingkungan keluarga setiap individu atau siswa memerlukan dukungan orang tua dalam mencapai prestasi belajar, karena dukungan dan perhatian keluarga ini akan menentukan seseorang siswa dapat mencapai prestasi belajar yang tinggi. Dukungan keluarga diwujudkan dalam hal kasih sayang, memberi nasehat-nasehat dan sebagainya Dukungan informasi dapat memberikan solusi dari masalah, memberikan nasihat, pengarahan, saran atau umpan balik tentang apa yang telah dilakukan anak. Hasil kuesioner yang diberikan kepada orang tua siswa (wali siswa), dukungan informasional orang tua atau wali terhadap anaknya rata-rata orang tua atau wali selalu memberikan nasihat kepada anaknya ketika melakukan sesuatu yang membahayakan dan memberikan nasehat untuk mentaati peraturan yang diberikan di sekolah (Freddy et al., 2021; Rahmadianti, 2020). Dukungan informational meliputi jaringan komunikasi dan tanggung jawab bersama termasuk didalamnya memberikan solusi dari masalah memberikan nasihat, pengarahan saran atau umpan balik tentang apa yang dilakukan. Keluarga juga menyediakan informasi dengan menyarankan tentang dokter terapi dan tindakan yang baik dan spesifik untuk mengontrol emosi keluarga. Pada dukungan informasi ini keluarga sebagai penghimpun informasi dan memberi informasi (Yulianingsih et al., 2020). Dukungan keluarga yang baik dapat meningkatkan prestasi belajar khususnya dalam pembelajaran online.

Pembelajaran online adalah pembelajaran dilakukan dengan bantuan internet baik secara sinkronus dan asinkronus yang memberikan kesempatan adanya interaksi peserta didik dengan sumber belajar baik pendidik/lingkungan serta teman sebayanya (Dong et al., 2020). Adanya pembelajaran online memberikan kesempatan kepada peserta didik untuk berbagi pendapat serta belajar lebih mandiri tanpa ada batas waktu dan ruang lebih bersifat fleksibel (Gwo Jen Hwang et al., 2020; Kkese, 2020; Lage-Cala et al., 2020). Pembelajaran daring adalah pembelajaran online sangat membutuhkan kemampuan pendidik dan peserta didik, karena dengan adanya kemampuan dalam menggunakan teknologi akan sangat membantu membuat suasana pembelajaran yang lebih kondusif, sehingga terbentuk interaksi social yang baik (Andel et al., 2020). Selain kemampuan tentunya pembelajaran online juga harus memperhatikan kondisi finansial dari peserta didik dan sarana dan prasarana yang menunjang pembelajaran online (Rusli et al., 2020). Serta dukungan orang tua sangat dibutuhkan disini baik dalam menyiapkan fasilitas maupun dukungan memberikan dorongan serta mendapingi dan membimbing siswa dalam proses pembelajaran. dengan dukungan yang baik dari orang tua tentunya akan berdapak terhadap prestasi siswa.

Prestasi belajar siswa dipengaruhi oleh dua faktor utama yaitu faktor internal dan faktor eksternal. Faktor internal faktor yang timbul dari dalam individu sendiri di dalam diantaranya adalah minat bakat motivasi dan tingkat intelegensi (Safitri \& Yuniwati, 2019). Faktor eksternal adalah segala bentuk pengaruh yang datang dari luar diri dan mempengaruhi kegiatan belajar seseorang diantaranya adalah keluarga sekolah dan faktor sosial (Aslan, 2021; Syafa'ati et al., 2021). Dukungan orang tua merupakan bantuan yang diberikan kepada anggota keluarga lain berupa barang jasa informasi dan nasehat yang membuat penerima dukungan akan merasa disayang dihargai dan merasa nyaman (Al Hakim, 2021; Safitri \& Yuniwati, 2019). Faktor dukungan orang tua atau keluarga merupakan dukungan penting dalam mendukung prestasi belajar anak dikarenakan dukungan orang tua terhadap anak dapat meningkatkan motivasi dalam belajar anak dan meningkatkan prestasi belajar anak

Jabaran-jabaan tersebut memberikan gambraan bahwa dukungan keluarga dengan kategoi yang baik mempengaruhi prestasi belajar anak sehingga prestasi belajar anak menjadi tinggi. Apabila prestasi belajar anak menurun akan menyebabkan anak mengalami kesulitan dalam menerima pembelajaran di kelas nya oleh karena itu anak juga membutuhkan hubungan keluarga orang terdekat untuk memberikan termotivasi untuk belajar. Temuan ini diperkuat dengan temuan sebelumnya yang menyatakan ada pengaruh dukungan keluarga terhadap prestasi belajar (Safitri \& Yuniwati, 2019). Selain itu, semakin tinggi dukungan keluarga maka semakin tinggi pula motivasi belajar siswa pada masa pandemi Covid-19 (Saragih et al., 2021). Dukungan keluarga juga memberikan kontribusi terhadap motivasi belajar siswa, dengan motivasi yang baik akan meningkatkan prestasi belajar siswa (Fitria \& Barseli, 2021). Keluarga memberikan pengaruh yang besar dalam keberhasilan belajar siswa (Sari, 2020). Penelitian ini hanya menggunakan jumlah sampel yang sedikit. Penelitian selanjutnya dalap menambahkan sampel yang lebih banyak, sehingga dapat menganalisis hubungan mengenai dukungan keluarga dengan prestasi belajar siswa kelas IV SDN 134 Pekanbaru dapat dilakukan intervensi untuk keluarga agar memberikan dukungan dalam proses belajar anak.

\section{SIMPULAN}

Dukungan orang tua sangat mempengaru prestasi belajar, dukungan oarang tua yang baik akan mendukung prestasi belajar siswa. Dukungan orang tua dapat diberikan dengan pemberian kasih sayang, 
tidak menutut dan memaksa siswa, serta menyediakan waktu untuk menamani dan membimbing siswa dalam proses pembelajaran mengingat pembelajaran saat ini adalah pembelajaran daring. Dari penelitian ini dapat dirokemdasikan bahwa orang tua harus siap membimbing siswa dalam proses pembelajaran karena dengan adanya bimbingan dari orang tua siswa akan belajar lebih baik.

\section{DAFTAR PUSTAKA}

Al Hakim, M. F. (2021). Peran guru dan orang tua: Tantangan dan solusi dalam pembelajaran daring pada masa pandemi COVID-19. Riwayat: Educational Journal of History and Humanities, 1(1), 23-32. https://doi.org/10.24372/jr.v4i1.19677.

Andel, S. A., de Vreede, T., Spector, P. E., Padmanabhan, B., Singh, V. K., \& Vreede, G. J. de. (2020). Do social features help in video-centric online learning platforms? A social presence perspective. Computers in Human Behavior, 113(April), 106505. https://doi.org/10.1016/j.chb.2020.106505.

Aslan, A. (2021). Problem- based learning in live online classes: Learning achievement, problem-solving skill, communication skill, and interaction. Computers \& Education, 171, 104237. https://doi.org/10.1016/j.compedu.2021.104237.

Astika, I. W. M., Suwindra, I. N. P., \& Mardana, I. B. P. (2018). Hubungan self-efficacy dan self-esteem dengan prestasi belajar fisika siswa di kelas x MIPA SMA Negeri. Jurnal Pendidikan Fisika Undiksha, 8(2), 77-85. http://dx.doi.org/10.23887/jjpf.v8i2.20642.

Choe, D. (2020). Parents' and adolescents' perceptions of parental support as predictors of adolescents' academic achievement and self-regulated learning. Children and Youth Services Review, 116, 105172. https://doi.org/10.1016/j.childyouth.2020.105172.

Curtis, K., Anicama, C., \& Zhou, Q. (2021). Longitudinal relations among school context, school-based parent involvement, and academic achievement of Chinese American children in immigrant families. Journal of School Psychology, 88, 1-17. https://doi.org/10.1016/j.jsp.2021.07.002.

Dong, C., Cao, S., \& Li, H. (2020). Young children's online learning during COVID-19 pandemic: Chinese parents' beliefs and attitudes. Children and Youth Services Review, 118(August), 105440. https: //doi.org/10.1016/j.childyouth.2020.105440.

Fitria, L., \& Barseli, M. (2021). Kontribusi Dukungan Keluarga terhadap Motivasi Belajar Anak Broken Home. JPGI Jurnal Penelitian Guru Indonesia), 6(1), 6-9. https: //doi.org/10.29210/02697jpgi0005.

Freddy, F., Lestari, S., \& Prihartanti, N. (2021). Self-regulated learning sebagai mediator keterlibatan orang tua dan prestasi akademik siswa SMA. Persona, 10(1), 1 - 15. https://doi.org/10.30996/persona.v10i1.4321.

Garbe, A., Ogurlu, U., Logan, N., \& Cook, P. (2020). Parents' Experiences with Remote Education during COVID-19 School Closures. American Journal of Qualitative Research, 4(3), 45-65. https: //doi.org/10.29333/ajqr/8471.

Hamdu, G. dan L. A. (2011). Pengaruh Motivasi Belajar Siswa Terhadap Prestasi Belajar IPA di Sekolah Dasar. Jurnal Penelitian Pendidikan, 12(1), 81-86. http://jurnal.upi.edu/file/8Ghullam_Hamdu.pdf

Hwang, G. J, Wang, S. Y., \& Lai, C. L. (2020). Effects of a social regulation-based online learning framework on students' learning achievements and behaviors in mathematics. Computers and Education, 160. https://doi.org/10.1016/j.compedu.2020.104031.

Hwang, Gwo Jen, Wang, S. Y., \& Lai, C. L. (2020). Effects of a social regulation-based online learning framework on students' learning achievements and behaviors in mathematics. Computers and Education, 160, 104031. https://doi.org/10.1016/j.compedu.2020.104031.

Inten, D. N. (2017). Peran Keluarga dalam Menanamkan Literasi Dini pada Anak. Golden Age: Jurnal Pendidikan Anak Usia Dini, 1(1), 23-32. https://doi.org/10.29313/ga.v1i1.2689.

Kkese, E. (2020). McGurk effect and audiovisual speech perception in students with learning disabilities exposed to online teaching during the COVID-19 pandemic. Medical Hypotheses, 144(July), 110233. https://doi.org/10.1016/j.mehy.2020.110233.

Kuswariningsih, S. (2016). Korelasi Kebiasaan Belajar, Kreatifitas Belajar dan Prestasi Belajar IPS. Jurnal $\begin{array}{llll}\text { Penelitian Dan } & \text { 389-395. }\end{array}$ https: //ejournal.unikama.ac.id/index.php/JPPI/article/view/1690/1367.

Lage-Cala, S., Folgueras-Díaza, M. B., Alonso-Hidalgoa, M., García-Menéndezb, D., \& Fernández-Garcíab, F. J. (2020). Investigation of the effectiveness of online learning tools for energy performance certificates preparation. Energy Reports, 6, 609-614. https://doi.org/10.1016/j.egyr.2019.09.034.

Lestari, A., Ma'wiyah, N., \& Ihsan, M. (2020). Kontribusi Dukungan Keluarga dan Teman Bergaul Terhadap Indeks Prestasi Kumulatif Mahasiswa Dengan Memperhatikan Intensitas Belajar. Al-Khwarizmi: 
Jurnal Pendidikan Matematika Dan Ilmu Pengetahuan Alam, 8(1), 51-60. https://doi.org/10.24256/jpmipa.v8i1.1318.

Mariyana, D. (2020). Peningkatan Prestasi Belajar IPA tentang Tata Surya melalui Penerapan Model Pembelajaran Kooperatif Tipe TAI (Team Assisted Individualization) bagi Peserta Didik Kelas VI Sekolah Dasar. Social, Humanities, and Educational Studies (SHEs): Conference Series, 3(4), 787792. https://doi.org/10.20961/shes.v3i4.54403.

Nur, A. S. (2016). Pengaruh Pola Asuh Orang Tua, Konsep Diri, dan Motivasi Berprestasi terhadap Prestasi Belajar Matematika Siswa Kelas IX SMP Negeri di kota Merauke. Suska Journal of Mathematics Education, 2(2), 89 - 96. https://doi.org/10.24014/sjme.v2i2.2067.

Perceka, A. L. (2020). Hubungan Motivasi Dan Dukungan Keluarga Dengan Keinginan Mahasiswa S1 Keperawatan Semester 8 Untuk Meneruskan Program Profesi Ners Di Stikes Karsa Husada Garut. Jurnal Ilmiah Pendidikan Dan Pembelajaran, 4(4), 1. http://dx.doi.org/10.23887/jipp.v4i1.23063.

Rahmadianti, N. (2020). Pemahaman Orang Tua Mengenai Urgensi Bermain Dalam Meningkatkan Perkembangan Sosial Anak Usia Dini. Early Childhood: Jurnal Pendidikan, 4(1), 57-64. https: //doi.org/10.35568/earlychildhood.v4i1.717.

Rizki, S. D., Susilawati, \& Mariam, I. (2017). Hubungan Pola Asuh Orang Tua dengan Prestasi Belajar Anak Usia Sekolah Dasar Kelas II dan III. Jurnal Keperawatan, 8(1), 74-84. https://media.neliti.com/media/publications/137978-ID.

Rusli, R., Rahman, A., \& Abdullah, H. (2020). Student perception data on online learning using heutagogy approach in the Faculty of Mathematics and Natural Sciences of Universitas Negeri Makassar, Indonesia. Data in Brief, 29, 105152. https://doi.org/10.1016/j.dib.2020.105152.

Safitri, F., \& Yuniwati, C. (2019). Pengaruh Motivasi dan Dukungan Keluarga terhadap Prestasi Belajar Mahasiswa Tingkat II Prodi D-III Kebidanan Universitas Ubudiyah Indonesia. Journal of Healthcare Technology and Medicine, 2(2), 154-161. https://doi.org/10.33143/jhtm.v2i2.248.

Saragih, M., Silitonga, E., Sinaga, T. R., \& Mislika, M. (2021). Hubungan Dukungan Keluarga dengan Motivasi Belajar Mahasiswa Selama Pandemi COVID-19. Jurnal Ilmiah Keperawatan Imelda, 7(1), 73-77. https://doi.org/10.2411/jikeperawatan.v7i1.49.

Sari, R. S., Rianti, Lutbis, A. A., \& Ismatul Hasanah. (2021). The effect of scheduled routine blood transfusions on learning achievement of children with thalassemia: A study from Tangerang District Indonesia. Enfermería Clínica, 31(2), S443-S446. https://doi.org/10.1016/j.enfcli.2020.09.042.

Sari, T. T. (2020). Self-Efficacy dan Dukungan Keluarga Dalam Keberhasilan Belajar Dari Rumah di Masa Pandemi Covid-19. Education Journal: Journal Educational Research and Development, 4(2), 127136. https://doi.org/10.31537/ej.v4i2.346.

Saripudin, E., Sari, I., \& Mukhtar, M. (2018). Using Macro Flash Animation Media on Motion Material to Improve Learning Achievement for Learning Science in Junior High School. , 4 (1),. Journal of Science Research and Learning, 4(1), 68-75. https://doi.org/10.30870/jppi.v4i1.3316.

Sunarti, S., Rahmawati, S., \& Wardani, S. (2016). Pengembangan Game Petualangan "Si Bolang” Sebagai Media Pembelajaran Tematik Untuk Meningkatkan Motivasi Dan Prestasi Belajar Siswa Kelas V Sekolah Dasar. Jurnal Cakrawala Pendidikan, 1(1), 58-68. https: //doi.org/10.21831/cp.v1i1.8365.

Syafa'ati, J. S. N., Sucipto, \& Roysa, M. (2021). Analisis Prestasi Belajar Siswa Pada Pembelajaran Daring di Masa Pandemi COVID-19. Jurnal Educatio, 7(1), 122-128. https://doi.org/10.31949/educatio.v7i1.882.

Yulianingsih, W., Suhanadji, S., Nugroho, R., \& Mustakim, M. (2020). Keterlibatan Orangtua dalam Pendampingan Belajar Anak selama Masa Pandemi Covid-19. Jurnal Obsesi : Jurnal Pendidikan Anak Usia Dini, 5(2), 1138-1150. https://doi.org/10.31004/obsesi.v5i2.740.

Yulianti, D., Khanafiyah, S., \& Sulistyorini, S. (2016). Inquiry-based science comic physics series integrated with character education. Jurnal Pendidikan IPA Indonesia, 5(1), 38-44. https://doi.org/10.15294/jpii.v5i1.5787. 